\title{
In vivo Development of Nicotinic Acetylcholine Receptor Channels in Xenopus Myotomal Muscle
}

\author{
J. L. Owens and R. Kullberg \\ Biology Department, University of Alaska, Anchorage, Alaska 99508
}

The development of acetylcholine receptor (AChR) channel function in Xenopus myotomal muscle was studied by singlechannel recordings from cell-attached patches of nonjunctional membrane in vivo. AChR channels were studied from the time of their first appearance on the muscle membrane until the time of full maturity of the muscle. Two predominant amplitude classes of AChR channels were observed with slope conductances of about 40 and $60 \mathrm{pS}$. During the first day after their initial appearance on the membrane, the smallconductance channels were the most numerous class on the muscle membrane. The large-conductance channels then began to be expressed in significant numbers and, over the next $2 \mathrm{~d}$, became the predominant channel type. The largeconductance class had an apparent mean open time of $\sim 0.7$ msec at resting potential, which remained constant throughout development. The small channel initially had an apparent open time of $\sim 3 \mathrm{msec}$ at resting potential, which decreased during development by about $50 \%$. The decrease in open time of the small channel was correlated in time with the increased expression of the large-conductance channels. Openings of the large-conductance channels were generally separated by closed intervals of more than $1 \mathrm{msec}$, whereas openings of the small-conductance channels were commonly interrupted by brief gaps of about $0.2 \mathrm{msec}$ duration. The duration of the brief gaps did not change during development.

Studies of amphibian and mammalian skeletal muscle have shown that nicotinic acetylcholine receptor (AChR) channels undergo functional changes during development (reviewed by Schuetze and Role, 1987). In general, there is an increase in AChR channel conductance and a decrease in open time as the muscle matures. The first evidence of such changes came from the analysis of ACh-induced noise recorded from muscle. Recordings from muscle membrane in rats (Sakmann and Brenner, 1978; Fischbach and Schuetze, 1980) and amphibia (Kullberg et al., 1981; Kullberg and Kasprzak, 1985) demonstrated a 3to 4-fold decrease in the open time of AChR channcls. These experiments revealed the chronology of change in gating during muscle development, but they gave no information about the conductances of the channels. With the advent of the single-

Received June 8, 1988; revised Aug. 1, 1988; accepted Aug. 2, 1988.

This work was supported by grants from NSF (BNS 8603870) and NIH (NS24078) to R.K. and by fellowships from NSF and NIH to J.L.O. We are grateful to Drs. Paul Brehm, Leslie Henderson, Yoshi Kidokoro, and Chris Lingle for their helpful comments on the manuscript.

Correspondence should be addressed to Iesse Owens, Biology Department, University of Alaska, 3211 UAA Drive, Anchorage, AK 99508.

Copyright (C) 1989 Society for Neuroscience $0270-6474 / 89 / 031018-11 \$ 02.00 / 0$ channel recording method, it was discovered that 2 different conductance classes of channels were expressed during development (Clark and Adams, 1981; Hamill and Sakmann, 1981; Kidokoro et al., 1982; Brehm et al., 1984a, b; Leonard et al., 1984; Siegelbaum et al., 1984). A small-conductance class of about $40 \mathrm{pS}$ was initially predominant on the membrane, while in older cells, the majority of channels had a conductance of 60 pS. Furthermore, it was found that these conductance classes differed in their gating properties, with the $40 \mathrm{pS}$ channels being open about 2- to 4-fold longer than the $60 \mathrm{pS}$ channels.

For technical reasons, single-channel studies of AChR development have mainly been confined to cultured muscle. The absence of overlying connective or epithelial tissue makes cultured muscle cells especially suitable for patch-clamp recording. However, to be sure that the processes of normal receptor dcvelopment are faithfully represented in cultured muscle, the essential conclusions from in vitro studies should be confirmed by single-channel data from normally developing muscle in vivo. Studies in vivo also offer an opportunity to relate the temporal changes in receptor function to other concurrent development changes in the animal.

The present study describes the single-channel properties of AChRs during their normal development in vivo. Myotomal muscle of Xenopus laevis was used for this study because of the extensive data available on synaptic currents and AChR development in this muscle, both in vivo and in vitro (Kullberg et al., 1980, 1981, 1985; Brehm et al., 1982, 1984a, b; Leonard et al., 1984; Kullberg and Kasprzak, 1985). In this paper, we describe the gating kinetics and conductances of AChRs on nonjunctional myotomal muscle membrane throughout the full range of muscle development. Our records extend from the time the receptors first appear in embryos, less than $1 \mathrm{~d}$ old, until the muscle is lost at metamorphosis. We compare AChR development in the intact animal with the results obtained in cell culture and discuss the temporal relationship between developmental changes in AChK function and synaptic currents. Preliminary reports of these results have appeared elsewhere (Kullberg ct al., 1986; Brchm ct al., 1988).

\section{Materials and Methods}

Rearing and staging of embryos and tadpoles. All experiments were performed in vivo on myotomal muscle of embryos and tadpoles of $X$. laevis. Embryos were produced by inducing mating of adult pairs with subcutaneous injections of human chorionic gonadotropin (Sigma). Embryos or young tadpoles used for experiments were reared in dechlorinated tap water in $60 \mathrm{~mm}$ petri dishes at about a dozen per dish. The animals were staged according to the criteria of Nieuwkoop and Faber (1967). The rate of development is significantly influenced by temperature, and therefore, the developing embryos and tadpoles were kept in an incubator for the first $4-5 \mathrm{~d}$ at $23^{\circ} \mathrm{C}$. Thereafter, the animals were 
transferred to 5 gallon aquaria and maintained at room tempcraturc, which was generally $22-24^{\circ} \mathrm{C}$. Under these conditions the animals developed well and at the approximate rate expected from Nieuwkoop and Faber (1967). Records were taken from embryos ranging in age from $21 \mathrm{hr}$ (stage 19) to just before resorption of the tail at the end of metamorphosis (stage 61). During the first $48 \mathrm{hr}$ after fertilization, the embryos develop rapidly, progressing through each developmental stage in 1-2 hr until about stage 30 . In order to minimize staging errors, the animals were staged just before dissection, and we began recording within a few minutes after the muscle was exposed. Usually the recordings were ended within 1-2 hr of staging. For embryos younger than stage 30 , records taken after $1 \frac{1 / 2}{\mathrm{hr}}$ following staging were considered to belong to the next stage.

Myotomal muscle. The cells of the myotomal muscle are short fibers, ranging in length from $100 \mu \mathrm{m}$ at the timc of synapsc formation (stagc 21 ) to about $300 \mu \mathrm{m}$ at early metamorphosis (stage 48-50). The cells are arranged in myotomes along the length of the tail, and synapses are located on each end of the cell near the myocommata (Kullberg et al., 1977; Chow, 1980; Chow and Cohen, 1983). Myotomal cells remain mononucleate until the onset of metamorphosis; then as metamorphosis proceeds, they become multinucleate, probably from fusion with satellite cells (Muntz, 1975). Myotomal muscle is resorbed completely by the end of metamorphosis.

Preparation of muscle for recording. During dissection and recordings, embryos and tadpoles were placed in a modified Ringer's solution containing (in mM): $110 \mathrm{NaCl}, 1.0 \mathrm{KCl}, 1.8 \mathrm{CaCl}_{2}$, and $8 \mathrm{HFPFS}$ adjusted to $\mathrm{pH} 7.4$ with $\mathrm{NaOH}$. Tetrodotoxin $(1 \mu \mathrm{g} / \mathrm{ml})$ was routinely added to the solution to immobilize the muscle. Older tadpoles were either pithed or decapitated prior to dissection. The myotomal muscle was exposed by removing the overlying epithelium with fine-tipped forceps, minutia pins, or glass dissecting probes. The muscle was secured to the bottom of a Sylgard (Dow-Corning)-covered petri dish with fine stainless steel pins or small clips. To improve visualization the preparation was usually enclosed in a 3 -sided Sylgard chamber, covered with a glass coverslip. This prevented impairment of optics by the meniscus around the recording electrode. The open side of the chamber allowed access for the recording electrode. The muscle was viewed at $200 \times$ through an upright compound microscope equipped with Hoffman interference optics.

High-resistance (>10 G $\Omega$ ) seals were readily obtained from younger myotomal muscle (stages 19-40) without the need for enzyme treatment to remove connective tissue. This was advantageous because most of the interesting developments in AChR function had already occurred before the time that enzyme treatment was necessary. All records from stages younger than 41 plus a few at stages up to 44 were obtained from muscle without enzyme treatment. Stable seals became progressively more difficult to obtain as the muscle aged. In order to remove adherent connective tissue and enhance the cleanliness of the muscle surface, older myotomal muscle was bathed in Ringer solution plus $1 \mathrm{mg} / \mathrm{ml}$ collagenase (Type I, Cooper CLS) for 5-30 min depending on age, and then washed 2-3 times with Ringer solution prior to recording.

Recording techniques. Standard single-channel recording techniques were used (Hamill et al., 1981). All recordings were obtained from cellattached patches, at nonjunctional regions of muscle membrane. Electrodes were made from borosilicate glass (WPI), pulled to an outer tip diameter of about $1 \mu \mathrm{m}$. The tips were bent under a microforge in order to approach the muscle vertically. Electrode tips were occasionally fire polished; however, for most experiments high-resistance seals formed readily without fire polishing. In some experiments, Sigmacote (Sigma) was applied to the electrode tip to reduce noise levels. The electrodes were filled with the samc salt solution as the bath plus $500 \mathrm{~nm} \mathrm{ACh}$, except for control experiments as noted in the Results. This concentration of ACh elicited sufficient channel activity for convenient analysis with minimal overlapping events. To form seals, slight negative pressure (0-25 cm water) was applied to the recording pipette after contact with the cell. Single-channel currents were amplified by a List EPC/7 patchclamp amplifier, Bessel-filtered at $3 \mathrm{kHz}$, and recorded on FM tape (7.5 ips, $0-5 \mathrm{kHz}$ bandwidth). Records were typically taken at 3-4 different applied pipette potentials ranging from 0 to $100 \mathrm{mV}$. All recordings were done at room temperature $\left(22-24^{\circ} \mathrm{C}\right)$.

Data analysis. Analysis was done off-line with an INDEC 11/73 Laboratory Display System. Sections of the tape-recorded single-channeled data were digitized at $10 \mathrm{kHz}$ and stored on disk. The frequency response of the complete recording system was tested by applying square current pulses to the head stage, via the test circuit of the EPC/7. The minimum square current pulse that produced a half-amplitude output signal was
$65 \mu$ sec. Input current pulses of $170 \mu \mathrm{sec}$ produced output signals that reached full amplitude. Open channel current amplitudes were measured by averaging the sample values which exceeded the half-amplitude threshold, not including the first and last sample points. With a sample interval of $100 \mu \mathrm{sec}$, the amplitude of any opening detected by 3 or more sample points above threshold was faithfully measured, within the limits of the recording noise. Therefore, the minimum open duration that we accepted for measurement was $300 \mu \mathrm{sec}$. An opening was considered to end when at least one sample point fell below the half-amplitude threshold. The minimum recorded gap length was $100 \mu \mathrm{sec}$, and we assumed that all detected gaps represented complete closures.

The amplitudes, open durations, and closed durations of the singlechannel events were measured automatically, followed by a manual review to check the accuracy of measurement. Overlapping events were excluded from the analysis. Scattcr plots of event amplitude versus duration were displayed for each record. In most cases, the events formed $1-4$ discrete clusters of points which allowed us to define the limits of the different amplitude classes. After defining these limits, histograms of current amplitudes and open and closed durations were compiled for each amplitude class.

All open and closed duration histograms were fitted with single- and double-exponential functions, by the method of maximum likelihood (Colquhoun and Sigworth, 1983). Open duration histograms were fitted over a range of $0.3-25.6 \mathrm{msec}$ and closed duration histograms over a range of $0.2-51.2 \mathrm{msec}$, with correction for missed events outside of these ranges. The single- and double-exponential functions were displayed simultaneously for each histogram, and their relative goodness of fit was evaluated by eye. Histograms were classified as single exponential when they were accurately fitted by single-exponential functions, and there was little or no discernible improvement in the fitted curve using 2 exponential components. Histograms were classified as double exponential when they were accurately fitted by 2-component functions and the single-exponential curves failed to describe the data. The fast and slow time constants of double-exponential histograms usually differed by a factor of 3 or more, reflecting our ability to visually resolve 2 components. We use the terms "mean open time" and "mean closed time" to refer to the maximum likelihood estimates of the time constants obtained from these histograms. The abbreviations, $\tau_{\text {single }}, \tau_{\text {fast }}$, and $\tau_{\text {slow }}$, refer to the time constants of single-exponential functions and the fast and slow time constants of the double-exponential functions.

For records that had closed duration histograms with 2 distinct kinetic components, we also calculated the mean burst duration of channel openings. A burst was defined as a series of successive channel openings separated by gaps of less than a critical length. The critical length depended on the time constants of the closed duration histogram and was defined according to $\exp \left(-t_{c} / t_{f}\right)+\exp \left(-t_{c} / t_{s}\right)=1$ (Colquhoun and Sakmann, 1985), where $t_{c}$ is the critical gap length, $t_{f}$ is the mean duration of brief gaps between channel openings, and $t_{s}$ is the mean duration of long gaps between channel openings. Unless stated otherwise, all data are expressed as means \pm standard deviation, and the sample sizes, given in parentheses, refer to the number of recording sites.

\section{Results}

AChR single-channel activity was recorded from myotomal muscle in embryos as young as $21 \mathrm{hr}$ (stage 19), the earliest age at which nicotinic AChRs are expressed on the muscle surface (Blackshaw and Warner, 1976; Kullberg et al., 1977; Chow and Cohen, 1983). Records were taken at each stage of development between stages 19-25 (a $6 \mathrm{hr}$ period) and at about every third or fourth stage over the next $25 \mathrm{~d}$ (stages 25-54). The oldest muscle studied was at stage 61 , which is $5 \mathrm{~d}$ before completion of metamorphosis.

The frequency of single-channel currents depended on the age of the muscle. When $500 \mathrm{~nm}$ ACh was present in the patch pipette, substantial channel activity was observed at stages 2548 in almost $100 \%$ of the patches. At very young stages (19$24)$ or older stages $(>48)$, some patches had no identifiable channel activity or else the event frequency was too low for analysis. This variability may reflect a lower density of nonjunctional AChR channels in very young and mature muscle relative to intermediate stages (Chow and Cohen, 1983). 


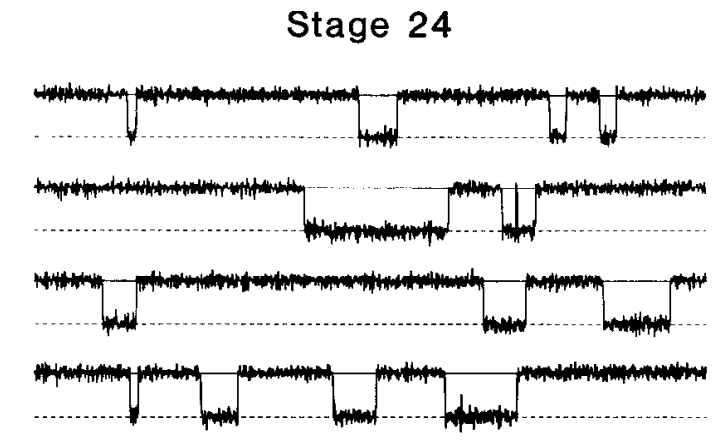

Stage 39

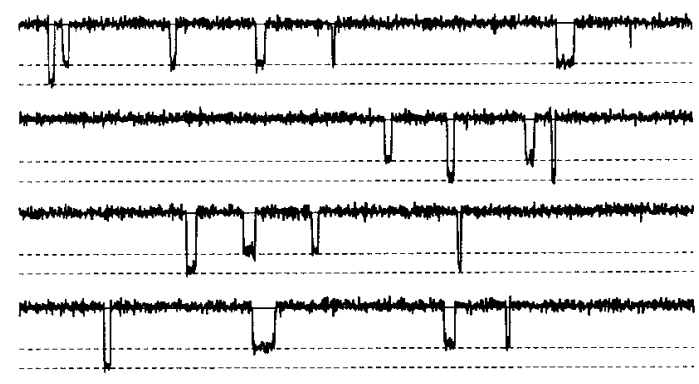

\section{Stage 61}

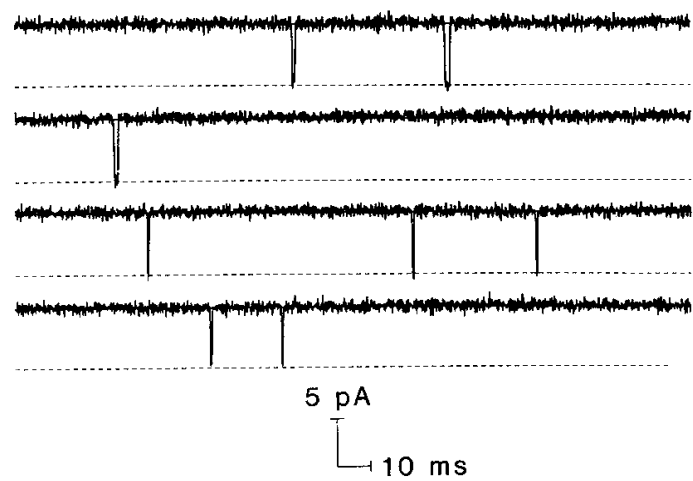

Figure 1. Examples of single ACh receptor channel openings recorded from nonjunctional regions of early, intermediate, and late stage myotomal muscle. Recordings were made at $40 \mathrm{mV}$ applied pipette potential from cell-attached patches. Dotted lines indicate the 40 and $60 \mathrm{pS}$ channel current amplitudes.

\section{Single-channel conductances}

When multiple openings were eliminated, the single-channel currents fell into 1-4 different amplitude classes. The 2 largest currents were predominant in most records. Occasionally it was possible to observe all 4 current levels in the same record, although usually only 2 or 3 levels were present. In records without overlapping events, openings of each amplitude class occurred in isolation. Rarely $(<1 / 1000)$ were events seen that could be interpreted as possible transitions from one amplitude class to another. This is in contrast to the more frequent partial closures of channels to subconductance states, reported in cultured muscle cells from rat (Hamill and Sakmann, 1981; Takeda and Trautmann, 1984; Sigworth, 1985), mouse (Morris and Montpetit, 1986), chick (Auerbach and Sachs, 1983, 1984), and adult frog muscle (Colquhoun and Sakmann, 1985). The smaller 2

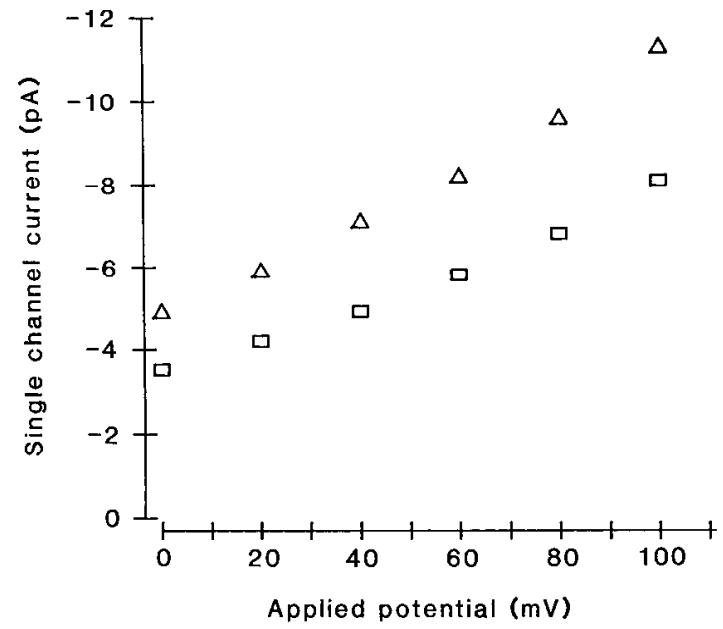

Figure 2. Single-channel current versus applied pipette potential. Channel currents are indicated by triangles (large channels) and squares (small channels). These data are taken from a single recording site at stage 40 . The nonlinearity of current versus voltage is evident in both channel types.

currents had slope conductances of 10-15 and 20-30 pS. Small, independent events have also been noted in recordings of AChR activity in cultured Xenopus muscle cells (Brehm et al., 1984a; Auerbach and Lingle, 1986). It is possible that these smaller events represent the openings of AChR channels; however, we have not yet characterized their properties in detail. For the remainder of this report only the 2 larger and more frequently encountered channel currents will be described.

The 2 major classes of $\mathrm{ACh}$ receptor channels that we observed during development resemble those previously reported in mature myotomal muscle (Brehm et al., 1984b). Currents belonging to the 2 classes are shown in Figure 1. Based on the cumulative data, the mean single-channel current amplitudes at resting potential were $3.28 \pm 0.60 \mathrm{pA}(128)$ and $4.54 \pm 0.83$ pA (68) for the 2 channel types. There was no development change in the single-channel current amplitudes. For instance, the mean current amplitude of the smaller amplitude channel was $3.17 \pm 0.61 \mathrm{pA}(65)$ at stages 19 to 30 and $3.39 \pm 0.57 \mathrm{pA}$ (63) at stages 33-61.

As noted previously (Brehm et al., 1984a, b) the currentvoltage $(I-V)$ relationships of both channel classes were nonlinear (Fig. 2). The slope conductances of both classes increased with membrane hyperpolarization. To better describe the dependence of conductance on membrane potential, we measured the slope conductance between successive $20 \mathrm{mV}$ steps of applied potential between 0 and $80 \mathrm{mV}$ (Fig. 3). The mean slope conductance of the smaller class was $35.2 \pm 8.8 \mathrm{pS}(79)$, measured between 0 and $20 \mathrm{mV}$, and $39.5 \pm 10.9 \mathrm{pS}$ (41) between 40 and 60 . At these same applied potentials, the conductances of the larger channels were $50.9 \pm 11.7 \mathrm{pS}(34)$ and $60.0 \pm 18.4$ pS (20). There was no change in the $I-V$ relationship of either channel during development. For the sake of convenience, we will refer to the 2 conductance classcs as " $40 \mathrm{pS}$ " and " $60 \mathrm{pS}$ " channels.

\section{Reversal potentials}

The reversal potentials for the 2 channel types were difficult to measure with confidence. Linear extrapolation of the $I-V$ relationship to the zero current level did not give a valid estimate 


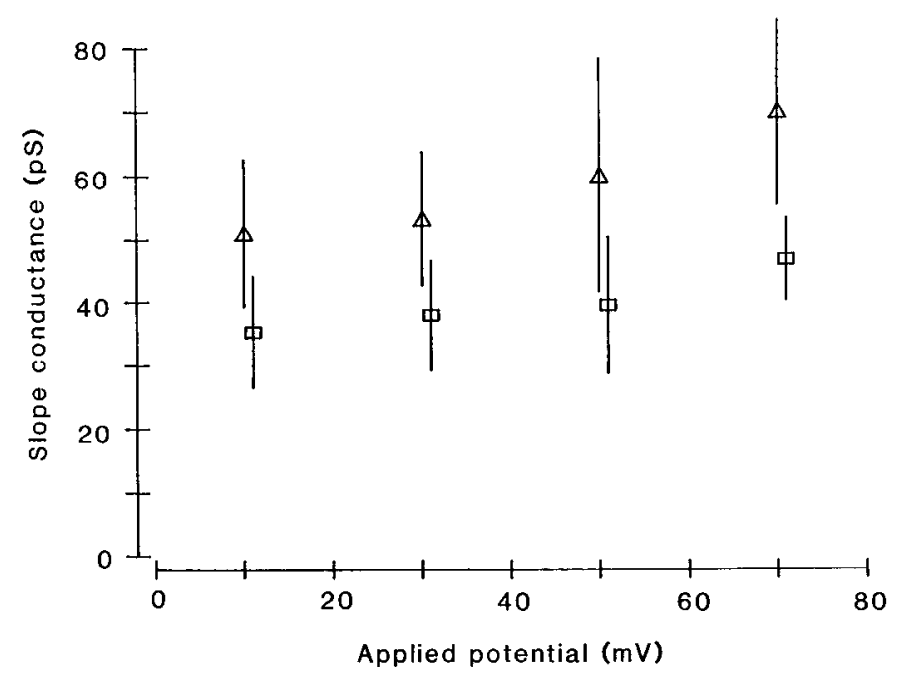

Figure 3. Mean slope conductance versus applied pipette potential for large (triangles) and small (squares) channels. Bars indicate SD. These values are based on the cumulative data from all recording sites throughout development. Recordings were taken at $0,20,40,60$, and $80 \mathrm{mV}$ applied potential. The slope conductances between adjacent $20 \mathrm{mV}$ applied potentials were calculated at each recording site and then averaged to obtain the mean values plotted here. The mean slope conductances are plotted midway between each $20 \mathrm{mV}$ interval.

because of the nonlinearity just mentioned. A further complication resulted from the voltage sensitivity in the open time of both channels. When the membrane was depolarized until currents disappeared or reversed, the channel open time became so rapid that most events were attenuated by the recording system. Nevertheless, we obtained a rough estimate of the reversal potentials by adjusting the applied pipette potential until the currents disappeared. At 11 different recording sites the channel currents disappeared at $-77 \pm 19 \mathrm{mV}$ applied potential. Assuming resting membrane potentials of about $-80 \mathrm{mV}$ (Kullberg et al., 1985), the zero current level occurs at a membrane potential near $0 \mathrm{mV}$.

\section{Developmental changes in conductance classes}

During early developmental stages (19-30), the predominant channel openings belonged to the $40 \mathrm{pS}$ class. Out of 78 recording sites, only 9 had evidence of significant $60 \mathrm{pS}$ channel activity. However, by stage 33 more than $60 \%$ of the recording sites had high-conductance channels, and thereafter this percentage progressively increased to over $95 \%$ in older muscle (stages 47-61). The relative frequency of $60 \mathrm{pS}$ events at individual recording sites also increased as the muscle developed. In Figure 4, current amplitude histograms illustrate the changing prevalence of the 2 channel types at different stages of development. The relative increase in frequency of high-conductance channel openings at all recording sites is summarized in Figure 5. From these data it appears that the major period of transition in channel types occurs after stage 30 . Several recordings from muscle older than stage 50 contained only the high-conductance channel. Our estimates of relative event frequency were based on the number of observed channel openings assigned to each class. Because a large number of events were missed, due to the frequency response of the recording system, and because of possible differences in agonist affinity (Auerbach and Lingle, 1987) and gating kinetics, these data do not necessarily represent the relative numbers of each channel type actually present in the

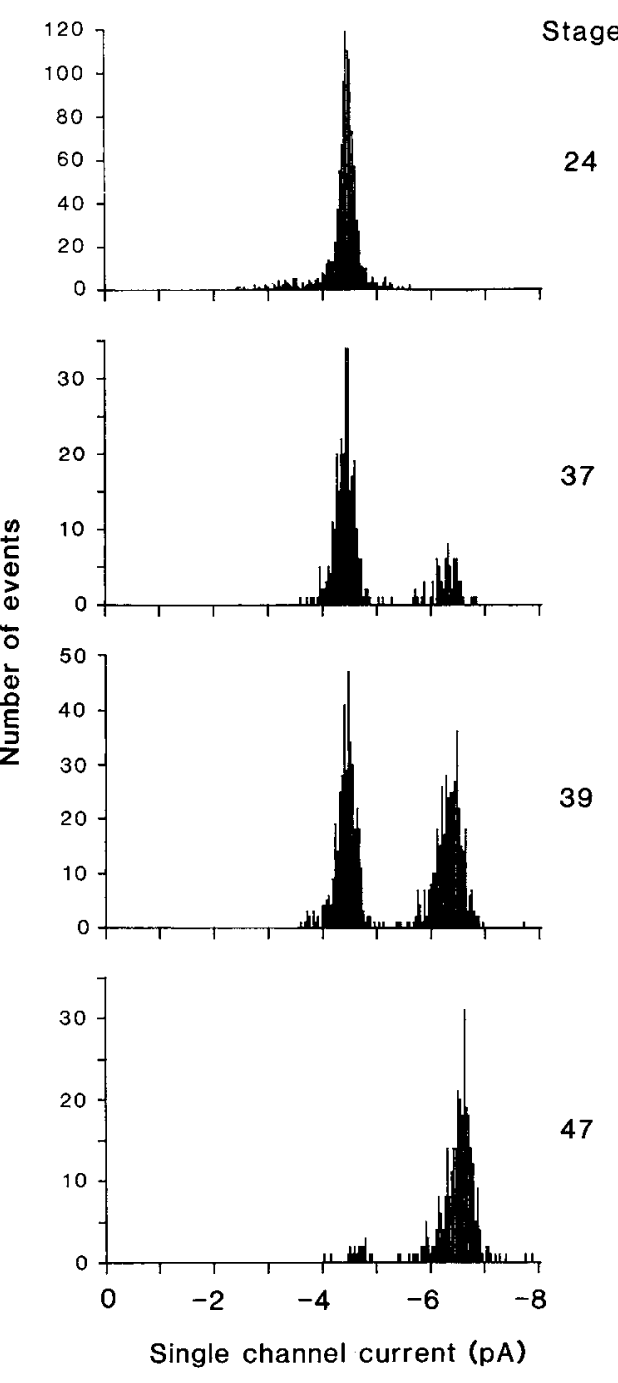

Figure 4. Amplitude histograms of single-channel currents at $40 \mathrm{mV}$ applied potential. These histograms reveal 2 amplitude classes of channels and demonstrate the increasing relative abundance of the largeamplitude events with development.

patches. Nevertheless, they support the general conclusion that large channels progressively outnumber the smaller ones during development of myotomal muscle and that this change mainly occurs following stage 30 .

\section{Developmental changes in apparent channel open time}

The open times of the $40 \mathrm{pS}$ channels became briefer during development, confirming previous observations made in vitro (Leonard et al., 1984). This change is illustrated by the singlechannel records shown in Figure 1 and the open duration histograms in Figure 6. Approximately half of the open duration histograms at all stages were adequately fitted by single-exponential functions. However, the fact that 2 exponential components were required to fit many of the histograms suggests that some or perhaps all of the apparently single-exponential histograms were composed of more than one kinetic component that we could not resolve. The time constants of individual open duration histograms are plotted against developmental stage in Figure 7 . There was a wide scatter of estimates at any single stage; however, a developmental trend toward faster open times of the $40 \mathrm{pS}$ channels was evident. Examination of the fast and 
Figure 5. Increase in relative percentage $60 \mathrm{pS}$ events versus developmental stage. Each data point represents the percentage of total observed channel openings belonging to the $60 \mathrm{pS}$ conductance class of AChRs. In most cases, data points at 0 and $100 \%$ represent multiple recording sites (up to 21 ) at a single stage. The data points from stages 19 to 25 represent a total of 59 recording sites at which negligible large-channel activity was detected. All other data points represent single recording sites.

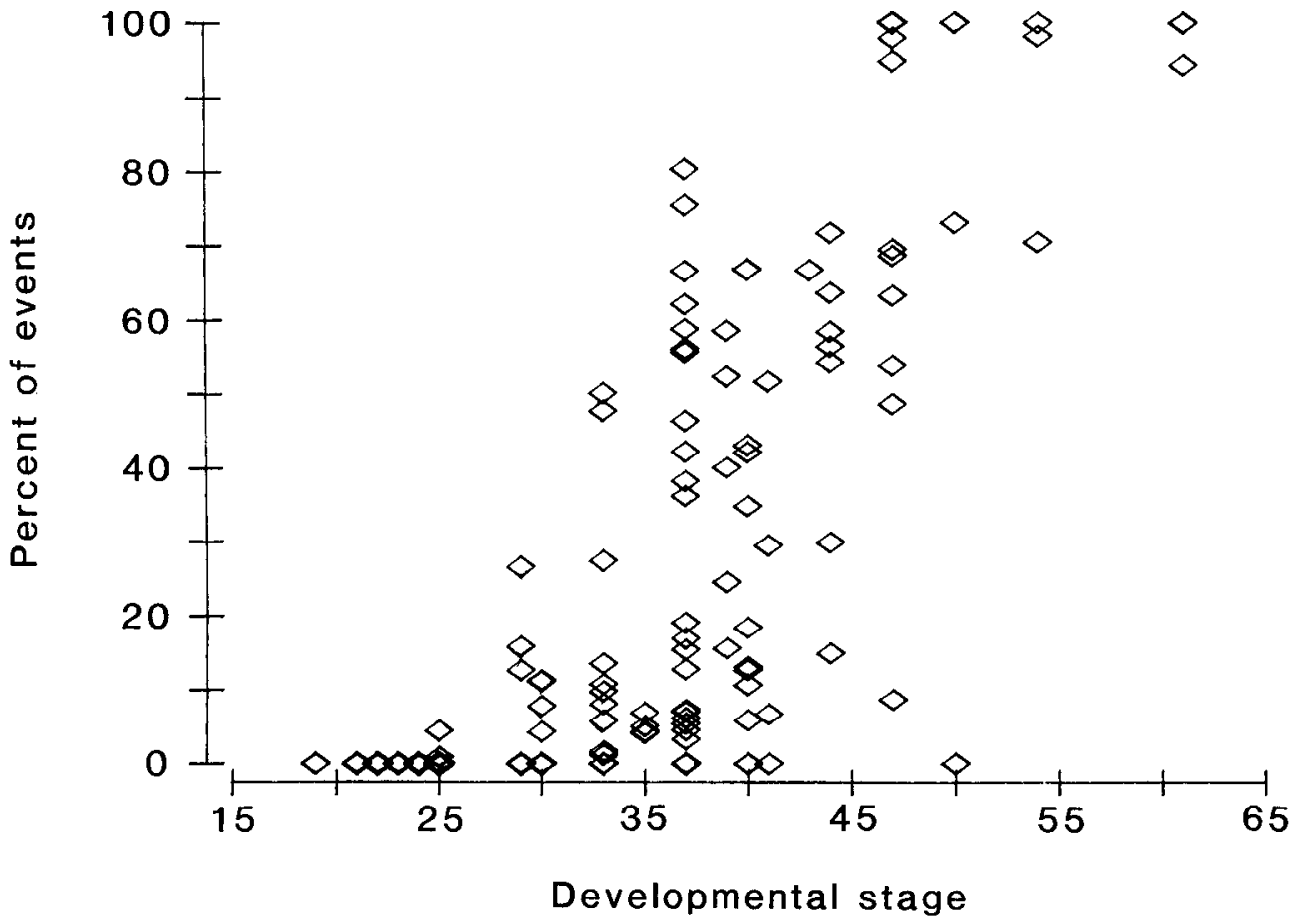

slow components of the double-exponential histograms suggests a transition to faster values following stage 30 , which coincides with the onset of expression of the $60 \mathrm{pS}$ channels. Using stage 30 as a dividing point, we have summarized the apparent open time data in Table 1. Overall, the apparent open times of the $40 \mathrm{pS}$ channels decreased by about $50 \%$ during development.

The majority of the $60 \mathrm{pS}$ channel open duration histograms were well fitted by single-exponential functions with an average time constant of about $0.7 \mathrm{msec}$ at $0 \mathrm{mV}$ applied potential (Table 1). No developmental change in open time was evident (Fig. 7). At $0 \mathrm{mV}$, about $10 \%$ of the histograms $(5 / 41)$ were fitted better by double-exponential functions. The fast component $(<0.1$ $\mathrm{msec}$ ) was evident in only the first 1 or 2 bins of the histograms, and therefore could not be confidently estimated. The mean time constant of the slow component at $0 \mathrm{mV}$ was $0.68 \pm 0.22$ $\operatorname{msec}(5)$.

The apparent channel open times of both the 40 and $60 \mathrm{pS}$ channels lengthened with hyperpolarization (Fig. 8, Table 2). There was considerable variability in our estimates of voltage dependency at individual sites; nevertheless, the effect of applied potential on the open times of the $40 \mathrm{pS}$ channels appeared to decrease slightly during development. At stages 19-30, an $e$-fold increase in open time was produced by $\sim 60 \mathrm{mV}$ hyperpolarization, while at stages older than 30 , an $e$-fold increase required $\sim 90 \mathrm{mV}$ hyperpolarization on the average. The voltage depen- dency of the $60 \mathrm{pS}$ channels ( $e$-fold change in open time per $\sim 60 \mathrm{mV}$ ) was somewhat greater than that of the $40 \mathrm{pS}$ channel at comparable stages. There is good agreement between the voltage sensitivities we observed and those reported by Brehm et al. (1984b). Igusa and Kidokoro (1987) observed that the open times of the $40 \mathrm{pS}$ channels were positively correlated with those of the $60 \mathrm{pS}$ channels, at a constant applied potential in cultured Xenopus muscle. We found a similar correlation in vivo. The correlation coefficient $(r)$ between the open times of the 40 and $60 \mathrm{pS}$ channels at resting potential was $0.67(n=16$, significant at the 0.01 level). As observed in cultured muscle, we found no significant correlation between open time and current amplitude at a constant applied potential $(r=0.08$ for $60 \mathrm{pS}$ channels, and $r=0.21$ for $40 \mathrm{pS}$ channels), which suggests that the correlated open times were not due to different cell membrane potentials.

\section{Closed-state kinetics}

The majority of $40 \mathrm{pS}$ channel closed duration histograms were well fitted by the sums of 2 exponential functions (Fig. 9). The time constant of the brief component was about $0.2 \mathrm{msec}$ on average at $0 \mathrm{mV}$ applied potential (Table 3) and did not change significantly during development. The percentage of gaps comprising the brief component declined slightly with age, from 28 to $19 \%$ (Table 3). The time constant of the slow component

Table 1. Apparent channel open times

\begin{tabular}{llllll} 
& \multicolumn{2}{l}{$40 \mathrm{pS}$ channels } & & & $60 \mathrm{pS}$ channels \\
${$\cline { 2 - 4 }$} }$ & $\tau_{\text {single }}(\mathrm{msec})$ & $\tau_{\text {fast }}(\mathrm{msec})$ & $\tau_{\text {slow }}(\mathrm{msec})$ & & $\tau_{\text {single }}(\mathrm{msec})$ \\
\hline $19-30$ & $3.24 \pm 1.07(20)$ & $1.22 \pm 0.62(19)$ & $4.06 \pm 1.19(19)$ & & - \\
$33-50$ & $1.81 \pm 0.96(19)$ & $0.50 \pm 0.40(19)$ & $2.31 \pm 0.81(18)$ & & $0.69 \pm 0.23(36)$
\end{tabular}

All data were obtained at $0 \mathrm{mV}$ applied potential. Values are given as the mean time constants \pm SD. Sample sizes are shown in parentheses and indicate the number of different recording sites. No values are reported for the $60 \mathrm{pS}$ channel at stages $19-30$ because the infrequency of events in this class precluded an accurate estimate of their open time. 

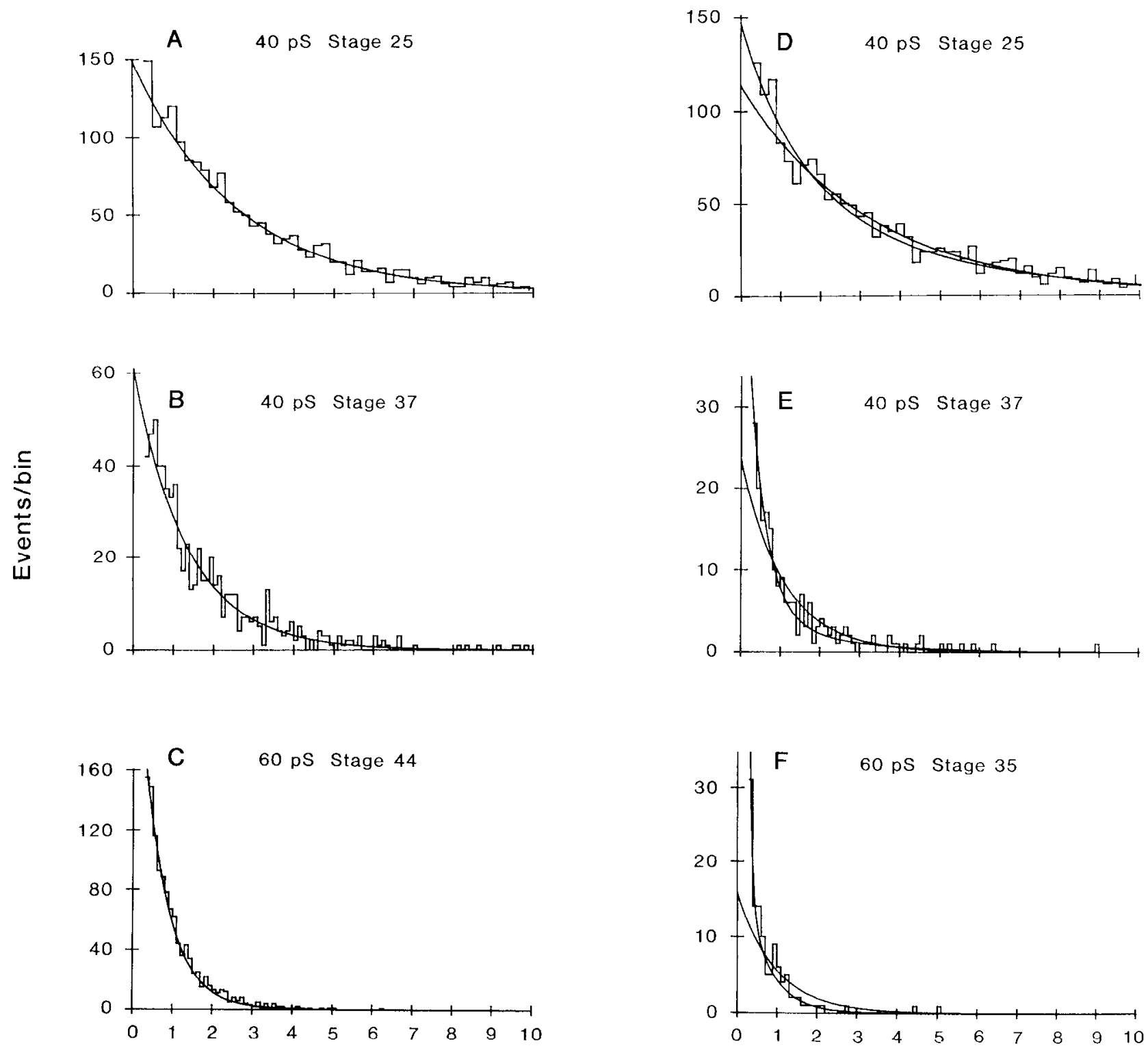

\section{Channel open time (ms)}

Figure 6. Open duration histograms of $\mathrm{ACh}$ receptor channels at different developmental stages. The developmental stage and channel type (40 or $60 \mathrm{pS}$ channels) are indicated by each histogram. All data were obtained at $0 \mathrm{mV}$ applied potential. Single-exponential histograms (A-C): On the left are displayed histograms that were satisfactorily fitted by single-exponential functions. The maximum likelihood estimate of a singleexponential function is superimposed on each histogram. Histograms $A$ and $B$ illustrate the decrease in $40 \mathrm{pS}$ channel open time that occurs during development of myotomal muscle; histogram $C$ was compiled from $60 \mathrm{pS}$ channel openings at stage 44 and illustrates the excellent fit to a singleexponential function seen in the majority of such recordings. The time constants of the fitted curves are as follows: $A, 2.70 \mathrm{msec} ; B, 1.41 \mathrm{msec}$; and $C, 0.67 \mathrm{msec}$. Double-exponential histograms $(D-F)$. Histograms on the right were fitted better by double-exponential functions. The maximum likelihood estimates of both single- and double-exponential functions are superimposed on each histogram. In each case, a double-exponential curve satisfactorily fits the data, while a single-exponential curve deviates noticeably from the data, particularly for brief events. The fast and slow time constants of the fitted curves are as follows: $D, 1.48$ and $4.31 \mathrm{msec} ; E, 0.44$ and $1.99 \mathrm{msec} ; F, 0.07$ and $0.62 \mathrm{msec}$.

varied widely and had a mean value of $40 \mathrm{~ms}$ (range, 7-226 msec at 38 sites, stages 19-44). In most cases, we were unable to resolve brief gaps in the openings of the $60 \mathrm{pS}$ channels. In 4 closed duration histograms (at 0 or $20 \mathrm{mV}$ applied potential) where a fast component was evident, the mean brief gap durations ranged from $\sim 0.1$ to $0.4 \mathrm{msec}$. The mean duration of long closed intervals was $113 \mathrm{msec}$ (range, 3-256 msec at 33 sites, stages 33-61).

\section{Burst kinetics}

The detection of brief closures in the records of $40 \mathrm{pS}$ channel activity allowed us to define bursts as successive openings separated by gaps of less than a critical length. A critical gap length of 0.9 msec was calculated (see Materials and Methods) using the average time constants of the fast and slow components of all closed duration histograms (0.22 and $40 \mathrm{msec})$. Burst du- 


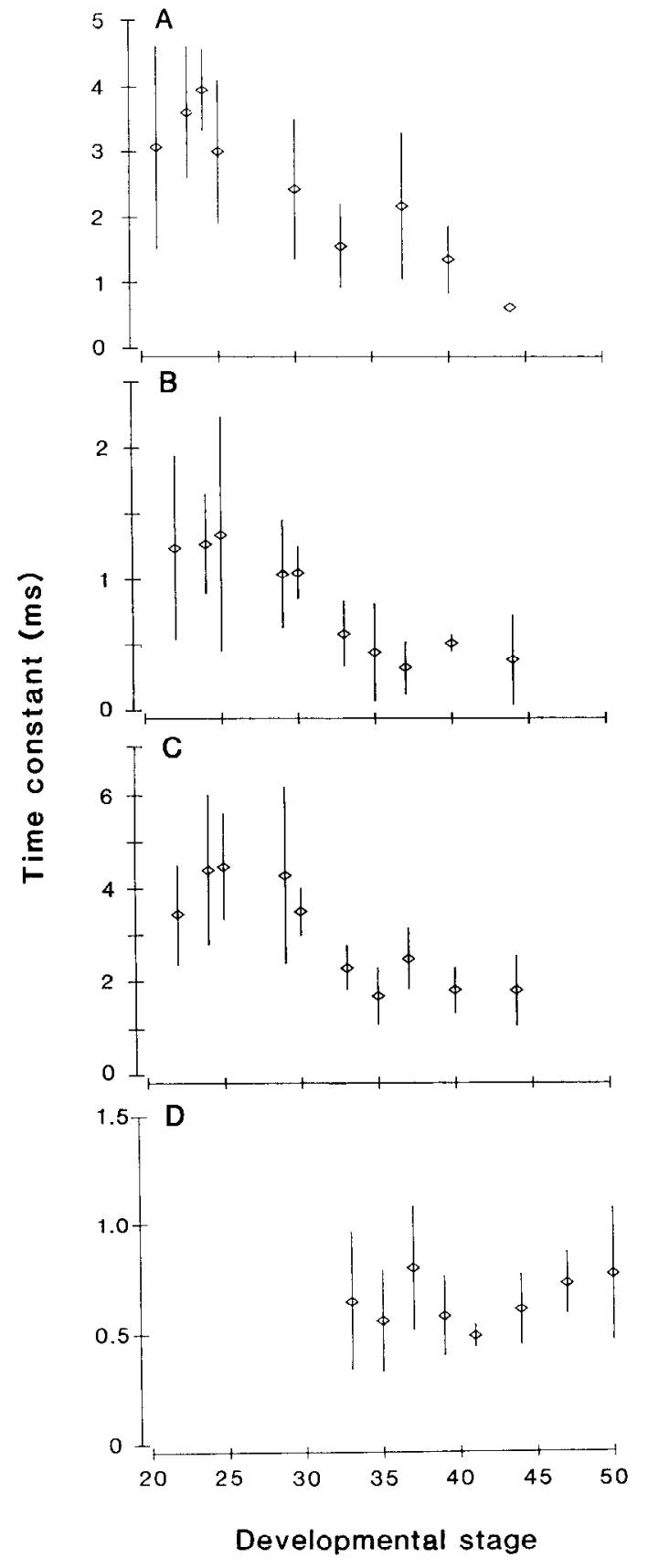

Figure 7. Apparent channel open time versus developmental stage. Each data point represents the mean $( \pm$ SD) time constant of open duration histograms at a single stage. The average number of histograms used to compute each data point was 4 (range, 1-12). $A$, Mean open time estimated from single-exponential open duration histograms of 40 $\mathrm{pS}$ channels. $B$, Mean open time estimated from the fast component of $40 \mathrm{pS}$ double-exponential histograms. $C$, Mean open time estimated from the slow component of $40 \mathrm{pS}$ double-exponential histograms. $D$, Mean single-exponential time constants of $60 \mathrm{pS}$ open duration histograms.

ration histograms were compiled for all $40 \mathrm{pS}$ records singleexponential open duration histograms. The mean burst duration declined from $3.95 \pm 1.46(20)$ at stages $19-30$ to $2.01 \pm 1.06$ (19) at stages 33-44. There was a somewhat greater tendency of the embryonic $40 \mathrm{pS}$ channels to reopen immediately following a closure, since the burst durations at early stages were about $22 \%$ longer than their corresponding apparent open durations

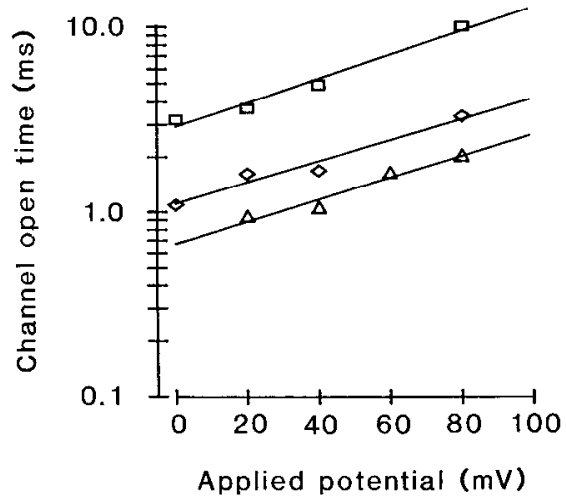

Figure 8. Mean channel open time versus applied pipette potential for 3 selected records from different kinetic classes of channels. Triangles, large-conductance channels at stage 54; diamonds, small-conductance channels at stage 33 ; squares, small-conductance channels at stage 23. These records further exemplify the differences between mean open time of the small channel at early and intermediate stages of development.

( 3.95 vs. $3.24 \mathrm{msec}$ ), while those at later stages were only about $11 \%$ longer ( 2.01 vs. $1.81 \mathrm{msec}$ ). The ratios of the percentage of brief gaps (Table 3 ) to the percentage of long gaps in the closed duration histograms imply that the average burst of the embryonic $40 \mathrm{pS}$ channel contained 1.39 openings, while the average burst at later stages (33-44) contained 1.23 openings. Dividing burst duration by the number of openings per burst, we estimate corrected channel open times of $2.84 \mathrm{msec}$ at stages $19-30$ and 1.63 msec at stages $33-44$ (as compared with apparent open times at those stages of 3.24 and $1.81 \mathrm{msec}$, respectively). Thus, the developmental change in burst duration reflects a significant change in the corrected channel open time and a small decrease in the number of openings per burst.

\section{Control experiments to identify AChR channels}

In order to confirm that the 40 and $60 \mathrm{pS}$ events represented the activity of $A C h R$ channels, recordings were made in the absence of $\mathrm{ACh}$ and also in the presence of high $(20 \mu \mathrm{M}) \mathrm{ACh}$ concentrations. In recordings without $\mathrm{ACh}$, precautions were taken to ensure that no $\Lambda \mathrm{Ch}$ remained in the recording dish or on the silver chloride wire electrode. In most recordings (19 out of 31 patches), no currents resembling those from the 40 or 60 $\mathrm{pS}$ channels were seen, but in others, channel activity occurred that was similar to that observed in the presence of agonist. In these records the event frequency was usually much higher as the seal formed and declined dramatically over the next minute to less than one event per second. These events could have been spontaneous openings of AChR channels. Others (Brehm et al., 1984a, b; Morris and Montpetit, 1986) have found similar AChRlike channel activity in the absence of agonist, and Jackson (1984) reported that AChR channels can open spontaneously. When the pipette contained $20 \mu \mathrm{M} \mathrm{ACh}$, channel openings of both conductance classes occurred in bursts, separated by long periods (seconds) of silence, which is typical of desensitized AChRs (Sakmann et al., 1980; Auerbach and Lingle, 1986, 1987; Igusa and Kidokoro, 1987).

The occurrence of spontaneous events in the absence of $\mathrm{ACh}$ prompted us to examine the effects on channel activity of $\alpha$-bungarotoxin $(\alpha$-BTX), a highly specific and essentially irreversible blocker of nicotinic AChRs. In two sets of experiments we determined which single-channel currents were abolished by a saturating dose (Brehm et al., 1983) of $\alpha$-BTX. These experi- 


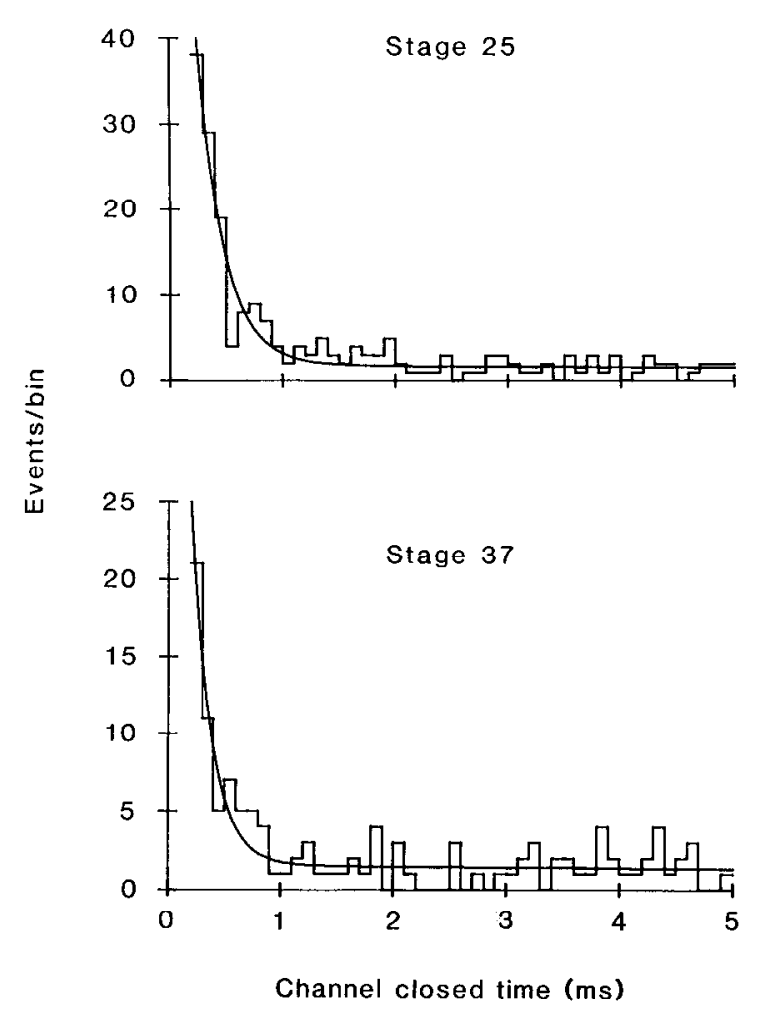

Figure 9. Closed duration histograms of $40 \mathrm{pS}$ AChR channels at stages 25 and 37 . These histograms were compiled from data obtained at 0 $\mathrm{mV}$ applied potential. Time constants were 0.24 and $29 \mathrm{msec}$ (stage 25) and 0.19 and $32 \mathrm{msec}$ (stage 37). The percentages of brief closures in the 2 histograms were $32 \%$ (stage 25) and $22 \%$ (stage 37 ).

ments were done on muscles that allowed rapid and stable seal formation without enzyme treatment and consistently exhibited substantial channel activity when ACh was present.

In the first set of experiments, 5 muscles were bathed for 15 $\min$ in $\alpha$-BTX $(0.1 \mathrm{mg} / \mathrm{ml})$ and 31 recordings with no agonist in the pipette were then obtained. Each recording was maintained at least $1.5 \mathrm{~min}$ (average, $2.4 \mathrm{~min}$ ). While recording, the patch was hyperpolarized $60-80 \mathrm{mV}$ from rest. During a total recording time of 75 min we saw no 40 or $60 \mathrm{pS}$ channel activity in these patches. In about $75 \%$ of the records $(23 / 31)$ the patch was completely silent, while in the remaining patches, events were seen which appeared to be due to stretch-activated channels.

In a second set of experiments we added $1.0 \mu \mathrm{M}$ ACh and $0.1 \mathrm{mg} / \mathrm{ml} \alpha$-BTX to the recording pipette to determine directly which channel activity was originally present before it was elim-
Table 3. Properties of brief closed intervals

\begin{tabular}{lll} 
Stages & $\tau_{\text {fast }}(\mathrm{msec})$ & $\begin{array}{l}\text { Percentage } \\
\text { of intervals }\end{array}$ \\
\hline $19-30$ & $0.21 \pm 0.07(24)$ & $28 \pm 10(24)$ \\
$33-44$ & $0.23 \pm 0.12(14)$ & $19 \pm 12(14)$
\end{tabular}

Data in this table were computed from closed duration histograms fitted by doubleexponential functions. Records were obtained at $0 \mathrm{mV}$ applied potential. Parameters were computed first at individual sites and then averaged. The percentage of brief closed intervals in cach histogram was based on extrapolation of the closed duration histograms to zero time. The difference in the percentage of brief closed intervals between stages $19-30$ and $33-44$ is significant at the 0.02 level (2-sided $t$ test).

inated by the toxin. In the presence of the toxin, channel activity often disappeared so rapidly that it was impossible to identify the events according to their slope conductance. However, in 39 recordings we collected enough events to identify which conductance classes were present in the patch before they were abolished by the toxin. The 40 and $60 \mathrm{pS}$ channel activity typically persisted for $<4 \mathrm{~min}$ before completely disappearing. At the end of some recordings, after a long period of toxin-induced silence, we were able to verify that the patch was still cellattached by breaking the cell membrane with negative pressure and observing spontaneous synaptic currents. In records taken from the same muscles, but with ACh and no toxin in the pipette, the event frequency remained high for the duration of the recordings, which was over $12 \mathrm{~min}$ in some cases. These results indicate that the 2 major conductance classes of events we commonly observed in our single-channel recordings were blocked by $\alpha$-BTX, implying that they were due to AChR channel openings.

\section{Stretch-activated channels}

Stretch-activated channels have been previously reported in Xenopus muscle in vivo (Brehm et al., 1984b) and in vitro (Brehm et al., 1984a) and other membranes (reviewed by Kullberg, 1987). In muscles that had been bathed in $\alpha$-BTX prior to recording, suction on the pipette elicited rapid bursts of openings with many unresolved closures in about $25 \%$ of patches. These channel openings had amplitudes comparable to those of AChR channels. Unlike the toxin-blockable channels, there was no noticeable change in the open time of these channels associated with increased hyperpolarization of the patch. The voltage-insensitive open times and toxin resistance suggest that the channels activated by suction are not AChRs. However, spontaneous openings of stretch-activated channels could be confused with openings of $\mathrm{AChR}$ channels because of their similar amplitudes. Therefore, in all recordings with agonist in the pipette, we rou-

Table 2. Voltage dependency of channel open time

\begin{tabular}{|c|c|c|c|c|}
\hline \multirow[b]{2}{*}{ Stages } & \multicolumn{3}{|l|}{$40 \mathrm{pS}$ channels } & \multirow{2}{*}{$60 \mathrm{pS}$ channels } \\
\hline & $\tau_{\text {single }}$ & $\tau_{\text {fast }}$ & $\tau_{\text {slow }}$ & \\
\hline $19-30$ & $61.4 \pm 22.5(9)$ & - & $66.5 \pm 32.0(5)$ & - \\
\hline $33-50$ & $88.9 \pm 34.8(17)$ & $78.5 \pm 53.5(18)$ & $75.4 \pm 42.4(18)$ & $62.6 \pm 32.7(33)$ \\
\hline
\end{tabular}

All values are given as the mean change $( \pm \mathrm{SD})$ in applied potential $(\mathrm{mV})$ per $e$-fold change in channel open time. Values were calculated at individual sites before averaging. No value is reported for the fast component at stages $19-$ 30 because of the wide scatter of values at individual sites. Pooled data at different potentials revealed no voltage dependency of this component. The difference in the $\tau_{\text {single }}$ voltage dependency of the 40 pS channel between stages $19-$ 30 and $33-61$ is significant at the 0.05 level by a 2-sided $t$ test. The difference in the $\tau_{\text {single }}$ voltage dependency between $60 \mathrm{pS}$ channels and $40 \mathrm{pS}$ channels at stages $33-50$ is significant at the 0.02 level. 
tinely tested for stretch-activated channels. Records showing such activity were not analyzed.

\section{Collagenase control experiments}

At all developmental stages through 40 , satisfactory recordings were routinely obtained from freshly dissected muscle without enzyme treatment. As development progressed, more connective tissue was deposited over the muscle surfaces, and brief treatment by collagenase $(1 \mathrm{mg} / \mathrm{ml}$ for $5-30 \mathrm{~min})$ was usually neccssary for rcliable scal formation. Howcver, recordings without collagenase treatment were occasionally obtained from stages as late as 44 . To determine if treatment of the muscle by collagenase (or other contaminating proteases) altered the properties of AChRs, we studied the effects of enzyme treatment at stages $37-40$, during which AChR activity could be examined with and without such treatment. The muscle was treated for 30 min in collagenase $(1 \mathrm{mg} / \mathrm{ml})$ and washed with Ringer's prior to recording.

There did not appear to be any effect of enzyme treatment on the slope conductance of either channel type. The slope conductances of the 2 classes were $39.5 \pm 8.9 \mathrm{pS}(10)$ and $57.0 \pm$ $9.1 \mathrm{pS}(5)$, between 40 and $60 \mathrm{mV}$ applied potential. The relative abundance of each channel was not significantly affected by enzyme treatment. Channels of the $40 \mathrm{pS}$ class were present in $90 \%$ of patches in both enzyme-treated muscle (11/12 patches) and control muscle (29/32 patches), while $60 \mathrm{pS}$ channels were present in $50 \%$ of patches $(6 / 12)$ in enzyme-treated muscle and $75 \%$ of patches $(24 / 32)$ in control muscle. The latter difference is not significant ( 2 sample proportion test). At recording sites where both types of channels were present, the relative numbers of observed events were similar in control and enzyme-treated cells. The percentage of observed high conductance events was $34 \%$ in collagenase-treated muscle (average of 6 sites) as compared with $40 \%$ in control muscle ( 24 sites).

The open-state kinetics of the $60 \mathrm{pS}$ channel did not appear to be affected by collagenase treatment. The channel open time at resting potential was $0.81 \pm 0.28 \mathrm{msec}(3)$. However, pronounced double-exponential distributions were found in each of 5 open duration histograms of $40 \mathrm{pS}$ channels in collagenasetreated muscle as compared with 18 out of 36 in control muscle. The slow time constant had a mean value of $3.01 \pm 1.18$ (5) at $0 \mathrm{mV}$, which was not significantly different from the control values (Table 1); however, the time constant of fast component was $0.20 \pm 0.09 \mathrm{msec}(5)$, which was about half that recorded in control muscle. In the collagenase-treated muscle, the brief openings made up $73 \pm 11 \%$ of the events, as compared with $51 \pm 22 \%$ in control recordings. Comparable fast components in the open duration histograms were not observed by Brehm et al. (1984), who studied AChR function in collagenase-treated muscle of late-stage Xenopus tadpoles; however, in view of a possible effect of enzyme treatment on the $40 \mathrm{pS}$ channel gating, we have limited our $40 \mathrm{pS}$ kinetic data to those recordings obtained without enzyme treatment.

\section{Discussion}

The single-channel properties of AChRs on myotomal musclc were studied from the time of their first appearance on the muscle until just before resorption of the muscle in metamorphosis. Myotomal muscle is the first muscle in Xenopus embryos to develop and becomes recognizable $\sim 19 \mathrm{hr}$ (stage 18) after fertilization. AChR activity was recorded as early as $21 \mathrm{hr}$ (stage 19), which is when AChRs can first be detected by binding of
${ }^{125} \mathrm{I}-\alpha$-BTX (Chow and Cohen, 1983) or by depolarization in response to bath applied ACh (Blackshaw and Warner, 1976; Kullberg et al., 1977). Stage 19 is $2 \mathrm{hr}$ prior to the first evidence of innervation (Blackshaw and Warner, 1976; Kullberg et al., 1977) and 5-6 hr before the muscle begins to contract (Nieuwkoop and Faber, 1967; Kullberg et al., 1977).

During the first $14 \mathrm{hr}$ (stage 19-30) after the initial appearance of AChRs, the membrane was dominated by channels with long open times $(\sim 3 \mathrm{msec})$ and low conductances $(35-40 \mathrm{pS})$. Noteworthy changes in channcl function bcgan less than $2 \mathrm{~d}$ after fertilization $(\sim$ stage 30$)$. At this time, we began to observe a class of high-conductance channels $(50-60 \mathrm{pS})$ with brief open times $(<1 \mathrm{msec})$ in many recordings, and as development progressed, these channels became the dominant ones on the myotomal muscle. Over the range of development during which large channels were abundant enough for analysis (stages 33-61), their conductance and gating properties remained constant. We observed no change in the conductance of the $40 \mathrm{pS}$ channels during development but found that their open times became about $50 \%$ briefer. The reduction in $40 \mathrm{pS}$ channel open time was correlated with the appearance of significant large channel activity, suggesting a possible coregulation of these events.

\section{Comparison of $A C h R$ development and endplate currents}

Endplate currents in myotomal muscle undergo a pronounced decrease in duration during development (Kullberg et al., 1980, 1985), which is probably due in part to changes in endplate AChR channel open time similar to those reported here for nonjunctional AChR channels. At recently formed synapses (stage 24), the decay constants of miniature endplate currents (MEPC's) are 6-9 msec, which is 2- to 3-fold longer than the channel open time at similar stages. This difference may be due to the absence of acetylcholinesterase (AChE) at these early synapses (Kullberg et al., 1980). The MEPC decays become faster between stages 24 and 30 , and $A C h E$ begins to accumulate at the synapse during this time. By stage 30 , the MEPC decay constants are about $3 \mathrm{msec}$, which corresponds to the channel open time that we measured at that stage. This suggests that AChE activity is then sufficient to limit the synaptic current decay to the apparent channel open time. Following stage 30 , there is a further decline in the MEPC duration, which parallels the increased expression of the fast-gating $60 \mathrm{pS}$ channels and the decrease in open time of the $40 \mathrm{pS}$ channels observed in nonjunctional membrane. The decay constants of MEPCs reach their briefest values at stages $47-50$ and stabilize at about 0.8 msec (Kullberg and Kasprzak, 1985), a value comparable to the measured apparent channel open time of $0.7 \mathrm{msec}$ for the 60 pS channels.

The close correspondence between MEPC decay constants and nonjunctional single-channel open times at stages 30 and older indicates that similar channels are found at junctional and nonjunctional regions throughout most or all of development. A similar conclusion was reached by comparison of $\mathrm{ACh}$ noise spectra at junctional and nonjunctional regions of developing myotomal muscle (Kullberg et al., 1981).

\section{Comparison of $A C h$ receptor development in vitro and in vivo}

Several studies of cultured Xenopus muscle have confirmed the existence of 2 amplitude classes of AChR channels (Kidokoro et al., 1982; Brehm et al., 1984a; Leonard et al., 1984; Auerbach and Lingle, 1986, 1987; Igusa and Kidokoro, 1987). The channel conductances were estimated by Brehm et al. (1984a, b) to be 
46 and $64 \mathrm{pS}\left(\right.$ at $23^{\circ} \mathrm{C}$ ), whilc at a lower recording temperature $\left(11-14^{\circ} \mathrm{C}\right)$, Leonard et al. (1984) found conductances of 25 and 43 pS. During development in culture, the larger-amplitude channels gradually become more numerous relative to the lower-amplitude channels. The $60 \mathrm{pS}$ channels in culture have open times of less than $1 \mathrm{msec}$ (corrected to the resting potential using the voltage sensitivity in Table 2), which do not change with the age of the culture (Brehm el al., 1984a, b). In cultures older than a day, estimates of the open time of the small channel range from 1 to $2 \mathrm{msec}$, corrected to the resting potential (Brehm et al., 1984a, Auerbach and Lingle, 1987; Igusa and Kidokoro, 1987). Leonard et al. (1984) recorded from cultures corresponding in age to stages 21-24 and stage 45 and found that the smallconductance channel open time decreased 3-fold over this age interval. These data suggest that the principal features of $\mathrm{AChR}$ channel development that occur in vivo also take place in cultured myotomal muscle.

We observed 2 components in the closed duration histograms of single $40 \mathrm{pS}$ AChR channel activity in vivo. The time constant of the brief component, $\sim 200 \mu \mathrm{sec}$, was similar to that reported by Igusa and Kidokoro (1987) in cultured muscle ( $300 \mu \mathrm{sec})$. The interpretation of brief closed intervals is debatable (Sine and Steinbach, 1987); however, if they represent transitions between doubly liganded open and closed states in the activation sequence of the channel, then the opening rate constant $(\beta)$ and agonist dissociation rate constant $\left(k_{-2}\right)$ can be estimated according to Colquhoun and Sakmann (1985), where the brief gap duration equals $1 /\left(\beta+2 k_{-2}\right)$ and the number of gaps/burst equals $\beta / 2 k_{-2}$. For the embryonic form of the $40 \mathrm{pS}$ channel, we estimate an opening rate constant of $\sim 1300 / \mathrm{sec}$ and an agonist dissociation rate of $\sim 1700 / \mathrm{sec}$. The estimated opening rate constant decreases with development to $\sim 800 / \mathrm{sec}$, while the dissociation constant remains nearly constant at $\sim 1800 / \mathrm{sec}$. The latter values are similar to those reported by Igusa and Kidokoro (1987) (510/sec and 2210/sec). However, those authors point out that their estimate of $\beta$, obtained from recordings with low ACh concentration $(0.2 \mu \mathrm{M})$, is inconsistent with their estimate of $\beta, 7800 / \mathrm{sec}$, obtained from the channel open probability during bursts of openings produced by high ACh concentration $(50 \mu \mathrm{M})$. Auerbach and Lingle (1987), using a faster sampling frequency, detected 3 components in the closed duration histograms. The fastest component, which they suggest is part of the activation sequence, had a time constant of about $40 \mu \mathrm{sec}$. They estimated an opening rate of $5600-7000 / \mathrm{sec}$ and a dissociation rate of $6700-8800 / \mathrm{sec}$. These values are consistent with the predicated channel open probability during bursts at high ACh concentrations. A $40 \mu \mathrm{sec}$ component would not have been detected in our recordings, so we have no direct evidence about the occurrence of such brief closures in vivo. In light of these results from cultured muscle, higher-resolution recordings will be necessary for satisfactorily describing the closed state kinetics in vivo.

\section{Molecular mechanisms of changes in AChR properties}

Two main features of receptor development need to be explained in terms of molecular mechanisms: the decrease in open time of the small channel and the emergence of channels with a high conductance and brief open time. So far, there is no evidence for a mechanism to account for the change in the open time of the $40 \mathrm{pS}$ channel. Agents that block protein synthesis do not appear to prevent the conversion to faster gating in vitro, suggesting that the change may take place in receptors that have already been inserted in the membrane (Carlson et al., 1985). On the other hand, the transition from low- to high-conductance channels may be transcriptionally controlled. In bovine muscle, substitution of an $\epsilon$ subunit in place of the $\gamma$ subunit in the receptor pentamer causes a switch to higher channel conductance and faster gating (Mishina et al., 1986). It has not yet been shown that this mechanism explains the development of highconduclance channels in Xenopus; however, a recent sludy of AChR subunit mRNA expression in myotomal muscle (Baldwin et al., 1988) revealed that the $\gamma$ transcript levels decline 50 -fold during the time that the $60 \mathrm{pS}$ channels become dominant on the membrane, whereas $\alpha$ and $\delta$ transcripts decline only about 3 - or 4-fold. It is possible that increased expression of $\epsilon$ mRNA during this period of development accompanies the decline in $\gamma$ mRNA, thereby maintaining receptor synthesis and endowing new receptors with higher conductance and faster open times. A test of this hypothesis awaits the cloning of the $c$ subunit gene in Xenopus.

\section{References}

Auerbach, A., and C. Lingle (1986) Heterogeneous kinetic properties of acetylcholine receptor channels in Xenopus myocytes. J. Physiol. (Lond.) 378: 119-140.

Auerbach, A., and C. J. Lingle (1987) Activation of the primary kinetic modes of large- and small-conductance cholinergic ion channels in Xenopus myocytes. J. Physiol. (Lond.) 393: 437-466.

Auerbach, A., and F. Sachs (1983) Flickering of a nicotinic ion channel to a subconductance state. Biophys. J. 42: 1-11.

Auerbach, A., and F. Sachs (1984) Single-channel currents from acetylcholine receptors in embryonic chick muscle. Kinetic and conductance properties of gaps within bursts. Biophys. J. 45: 187-195.

Baldwin, T. J., C. M. Yoshihara, K. Blackmer, C. R. Kintner, and S. J. Burden (1988) Regulation of acetylcholine receptor transcript expression during development in Xenopus laevis. J. Cell Biol. 106. 469-478.

Blackshaw, S., and A. Warner (1976) Onset of acetylcholine sensitivity and endplate activity in developing myotome muscles of Xenopus. Nature 262: 217-218.

Brehm, P., J. H. Steinbach, and Y. Kidokoro (1982) Channel open time of acetylcholine receptors on Xenopus muscle cells in dissociated cell culture. Dev. Biol. 91: 93-102.

Brehm, P., E. Yeh, J. Patrick, and Y. Kidokoro (1983) Metabolism of acetylcholine receptors on embryonic amphibian muscle. J. Neurosci. 3: 101-107.

Brehm, P., Y. Kidokoro, and F. Moody-Corbett (1984a) Acetylcholine receptor channel properties of Xenopus muscle cells in culture. J. Physiol. (Lond.) 357: 203-217.

Brehm, P., R. Kullberg, and P. Moody-Corbett (1984b) Properties of non-junctional acetylcholine receptor channels on innervated muscle of Xenopus laevis. J. Physiol. (Lond.) 350: 631-648.

Brehm, P., J. Lechleiter, L. Henderson, J. Owens, and R. Kullberg (1988) Development and regulation of acetylcholine receptor function. In Calcium and Ion Channel Modulation, A. D. Grinnell, D. Armstrong, and M. B. Jackson, eds., pp. 345-358, Plenum, New York.

Carlson, C. G., R. J. Leonard, and S. Nakajima (1985) The aneural development of the acetylcholine receptor in the presence of agents which block protein synthesis and glycosylation. Soc. Neurosci. Abstr. 11: 156 .

Chow, I. (1980) Distribution of acetylcholine receptors in the myotomes of Xenopus laevis during normal development. Doctoral thesis, McGill University, Montreal.

Chow, I., and M. W. Cohen (1983) Developmental changes in the distribution of acetylcholine receptors in the myotomes of Xenopus laevis. J. Physiol. (Lond.) 339: 553-571.

Clark, R. B., and P. R. Adams (1981) ACh receptor channel populations in cultured Xenopus myocyte membrane are non-homogeneous. Soc. Neurosci. Abstr. 7: 838.

Colquhoun, D., and B. Sakmann (1985) Fast events in single-channel currents activated by acetylcholine and its analogues at the frog muscle end-plate. J. Physiol. (Lond.) 369: 501-557. 
Colquhoun, D., and F. J. Sigworth (1983) Fitting and statistical analysis of single channel records. In Single-Channel Recording, B. Sakmann and E. Neher, eds., pp. 191-263, Plenum, New York.

Fischbach, G. D., and S. M. Schuetze (1980) A post-natal decrease in acetylcholine channel open time at rat end-plates. J. Physiol. (Lond.) 303: 125-137.

Hamill, O. P., and B. Sakmann (1981) Multiple conductance states of single acetylcholine receptor channels in embryonic muscle cells. Nature 294: 462-464.

Hamill, O. P., A. Marty, E. Neher, B. Sakmann, and F. Sigworth (1981) Improved patch-clamp techniques for high resolution current recording from cells and cell-free membrane patches. Pfluegers Arch. 391: $85-100$.

Igusa, Y., and Y. Kidokoro (1987) Two types of acetylcholine receptor channels in developing Xenopus muscle cells in culture: Further kinetic analysis. J. Physiol. (Lond.) 389: 271-300.

Jackson, M. B. (1984) Spontaneous openings of the acetylcholine receptor channel. Proc. Natl. Acad. Sci. USA 81: 3901-3904.

Kidokoro, Y., P. Brehm, and R. Gruener (1982) Developmental changes in acetylcholine receptor properties. In Muscle Development: Molecular and Cellular Control, M. L. Pearson and H. F. Epstein, eds., pp. 497-506, Cold Spring Harbor, New York.

Kullberg, R. (1987) Stretch-activated ion channels in bacteria and animal cell membranes. Trends Neurosci. 10:387-388.

Kullberg, R., and H. Kasprzak (1985) Gating kinetics of nonjunctional acetylcholine receptor channels in developing Xenopus muscle. $\mathrm{J}$. Neurosci. 5: 970-976.

Kullberg, R., and J. L. Owens (1986) Comparative development of endplate currents in two muscles of Xenopus laevis. J. Physiol. (Lond.) 374: 413-427.

Kullberg, R., T. Lentz, and M. W. Cohen (1977) Development of myotomal neuromuscular junction in Xenopus laevis: An electrophysiological and fine-structural study. Dev. Biol. 60: 101-129.

Kullberg, R., F. S. Mickelberg, and M. W. Cohen (1980) Contribution of cholinesterase to developmental decreases in the time course of synaptic potentials at an amphibian neuromuscular junction. Dev. Biol. 75: 255-267.

Kullberg, R., P. Brehm, and J. H. Steinbach (1981) Nonjunctional acetylcholine receptor channel open time decreases during development of Xenopus muscle. Nature 289: 411-413
Kullberg, R., J. L. Owens, and J. Vickers (1985) Development of synaptic currents in immobilized muscle of Xenopus laevis. J. Physiol. (Lond.) 364: 57-68.

Kullberg, R., J. L. Owens, and P. Brehm (1986) Development of nicotinic acetylcholine receptor function. Proc. IEEE/EMBS, 8th Annual Conference, pp. 948-950.

Leonard, R. J., S. Nakajima, Y. Nakajima, and T. Takahashi (1984) Differential development of two classes of acetylcholine receptors in Xenopus muscle in culture. Science 226: 55-57.

Mishina, M., T. Takai, K. Imoto, M. Noda, T. Takahashi, S. Numa, C. Methfessel, and B. Sakmann (1986) Molecular distinction between fetal and adult forms of musclc acetylcholine receptor. Nature 321: 406-411.

Morris, C. E., and M. Montpetit (1986) Multiple conductance states of the acetylcholine receptor complex. Can. J. Pharmacol. 64: 347355.

Muntz, L. (1975) Myogenesis in the trunk and leg during development of the tadpole of Xenopus laevis (Daudin 1802). Embryol. Exp. Morphol. 33: 757-774.

Nieuwkoop, P. D., and J. Faber (1967) Normal Table of Xenopus laevis, 2nd ed., North-Holland, Amsterdam.

Sakmann, B., and H. R. Brenner (1978) Changes in synaptic channel gating during neuromuscular development. Nature 276: 401-402.

Sakmann, B., J. Patlak, and E. Neher (1980) Single acetylcholineactivated channels show burst-kinetics in presence of desensitizing concentrations of agonist. Naturc 286: 71-73.

Schuetze, S. M., and L. W. Role (1987) Developmental regulation of nicotinic acetylcholine receptors. Annu. Rev. Neurosci. 10:403-457.

Siegelbaum, S. A., A. Trautmann, and J. Koenig (1984) Single acetylcholine-activated channel currents in developing muscle cells. Dev. Biol. 104: 366-379.

Sigworth, F. J. (1985) Noise in acetylcholine receptor currents suggests conformational fluctuations. Biophys. J. 47: 709-720.

Sine, S. M., and J. H. Steinbach (1986) Acetylcholine receptor activation by a site-selective ligand: Nature of brief open and closed states in BC3H-1 cells. J. Physiol. (Lond.) 370: 357-379.

Takeda, K., and A. Trautmann (1984) A patch-clamp study of the partial agonist actions of tubocurarine on rat myotubes. J. Physiol. (Lond.) 349: 353-374. 